\title{
Minimally invasive atrioventricular valve surgery - current status and future perspectives
}

\section{J. van der Merwe ${ }^{*}$, , F. Casselman* and F. van Praet}

*Department of Cardiovascular and Thoracic Surgery, OLV Clinic, Aalst, Belgium

\#Atlantic Cardiovascular and Thoracic Institute, Sunningdale, Cape Town, South Africa

Address for correspondence:

Johan van der Merwe

Atlantic Cardiovascular and Thoracic Institute

Netcare Blaauwberg Hospital

Sunningdale

Cape Town

7441

South Africa

Email:

drjohan@acvti.co.za

\section{INTRODUCTION}

We are currently witnessing rapid evolution in the development, marketing and utilisation of robotic, ${ }^{(1-3)}$ endoscopic ${ }^{(4-5)}$ and trans-catheter ${ }^{(6-9)}$ atrioventricular valve (AVV) repair and replacement technology as alternatives to classic sternotomy access (CSA). Collectively, minimally invasive atrioventricular valve surgery (MIAS) is associated with significant learning curves, ${ }^{(10)}$ which in the context of increasing patient age, operative risk profiles, expectations and strict quality control, , $^{(1-13)}$ potentially deter upcoming centres from incorporating MIAS programmes that utilise videoscopic or robotic vision, modified instruments, perfusion and myocardial protective strategies into clinical practice. As a result, CSA is still considered by many as the standard approach for AV disease, and subsequent reports have emerged that challenge the historically documented potential benefits associated with MIAS.(14) In addition, sceptics may prefer interventionist driven trans-catheter intervention ( $\mathrm{TCl}$ ) programmes to avoid the transitional challenges associated with establishing MIAS programmes. ${ }^{(15)}$ Various experienced MIAS centres reported their routine use of MIAS for all isolated AV pathology with excellent long-term results, (16-17) but whether their clinical outcomes can indeed be translated into general international surgical practice are not well defined.(18-20) This paper describes the historic evolution of MIAS, the contemporary clinical outcomes of MIAS compared

\section{ABSTRACT}

We are currently witnessing rapid evolution in minimally invasive and catheter-based atrioventricular valve interventions as acceptable alternatives to classic sternotomy access (CSA). Collectively, minimally invasive atrioventricular valve surgery (MIAS) is associated with significant learning curves and its routine application is met with varying degrees of enthusiasm in view of strict quality control, clinical governance and outcome reporting. Whether the reported potential benefits and comparable efficacy across a range of long-term outcome measures reported by experienced MIAS centres can be translated into general international surgical practice, are not well defined. This paper describes the historic evolution of MIAS, the contemporary clinical outcomes of MIAS compared with CSA, and the application of MIAS in "real-life" general practice.

SAHeart 2019;1 6:310-316

with CSA, and the application of MIAS in "real-life" general practice.

\section{REVIEW CRITERIA}

Contemporary, peer reviewed reports on minimally invasive mitral and tricuspid valve surgery were selected and reviewed for intra-operative, in-hospital, post-discharge and health economic outcomes and references.

\section{THE HISTORICAL EVOLUTION OF MIAS}

In the British Medical Journal of 1898, Daniel Samways became the first physician to propose that rheumatic mitral valve (MV) stenosis be treated by surgical intervention. Sir Lauder Brunton subsequently developed and reported his animal model of trans-ventricular mitral commisurotomy in 1902,(21) which was clinically applied as the first successful AVV surgical operation by Elliot Carr Cutler and Samuel Levine in 1923. (22) The 12-yearold patient survived for 4 years before passing away of pneumonia, but the poor outcomes of the subsequent 7 patients resulted in a procedural moratorium in 1929.(23)

The introduction of cardiopulmonary bypass in 1956 enabled safe intra-cardiac AVV access, with Duboist and Guiraun introducing the concepts of a trans-septal bi-atrial(24) and right atrial approaches ${ }^{(25)}$ respectively. The visionary repair concepts of 
MV regurgitation were proposed and refined by Davila, ${ }^{(26)}$ Nichols, ${ }^{(27)}$ Kay, ${ }^{(28)}$ Carpentier, ${ }^{(29)}$ McGoon ${ }^{(30)}$ and many others. ${ }^{(31)}$

Navia and Gosgrove ${ }^{(32)}$ were the first to report the concept and outcomes of a non-sternotomy, parasternal MV approach in 25 patients in 1996. There were no hospital deaths, reoperations for bleeding, embolic complications or wound infection. Cohn and his group also described their similar findings with this approach in 43 patients. ${ }^{(33)}$

The reported success of laparoscopy in general surgery resulted in the application and development of video assisted thoracic surgery, which provided Alain Carpentier and his team with the opportunity to perform the first video-assisted, right minithoracotomy MV-repair using ventricular fibrillation in 1996, ${ }^{(34)}$ which subsequently provided the platform for various centres to refine and further develop MIAS.

Port Access ${ }^{\mathrm{TM}}$ surgery (PAS), which consists of peripheral cardiopulmonary bypass (CPB), guidewire directed anterograde endo-aortic balloon occlusion (EABO), venting, cardioplegia delivery and videoscopic guidance of routine AVV procedures through a $4 \mathrm{~cm}$ right antero-lateral working, was initially developed by Heartport, Inc. (Redwood City, CA, USA) in 1994, and was introduced by Stevens and colleagues as a surgical method for performing bypass grafting. (35)

The teams of Frederick Mohr, ${ }^{(36)}$ Hugo Vanermen ${ }^{(37-38)}$ and others ${ }^{(39-40)}$ refined and incorporated PAS techniques into their routine MIAS clinical practice and reported the significant potential benefits in their extensive series. As an alternative to $E A B O$, direct aortic clamping (DAC) was introduced by Angouras and Michler ${ }^{(41)}$ and further developed by Chitwood. ${ }^{(42-44)}$

Recent developments in MIAS access include the introduction of a right vertical infra-axillary thoracotomy ${ }^{(45)}$ and a peri-arealor incision approach ${ }^{(46)}$ - with excellent results.

Carpentier performed the first completely robotic MV procedure using the Da Vinci Surgical System (Intuitive Surgical, Inc. Sunnyvale, California, USA), ${ }^{(46)}$ with various international groups now performing robotic AVV surgery as a routine with excellent reported outcomes. ${ }^{(47-48)}$

\section{CONTEMPORARY CLINICAL OUTCOMES OF MIAS COMPARED WITH CSA}

\section{Cardiopulmonary bypass, ischaemic and procedure times}

The pathophysiological and inflammatory effects of CPB and cardioplegic arrest for CSA and MIAS are well described. ${ }^{(49)}$
Various reports suggest that MIAS is associated with up to I5\% longer $\mathrm{CPB}$, ischaemic and procedure times compared to CSA for both simple and complex AVV surgical procedures. ${ }^{(50-61)}$ The transition to using single shaft instruments through limited working space and other technical factors are reported as possible contributing factors in the early experience. ${ }^{(62-63)}$

\section{Success of complex repair and replacement procedures}

The group from Aalst reported their MIAS series of 2872 patients, ${ }^{(64)}$ of which 2183 (76.0\%), 54 (1.9\%) and 635 (22.1\%) underwent isolated MV, isolated TV and combined MV and TV procedures. MV-repair was achieved in $96.4 \%(n=1822$ of $\mid 89$ I) of primary annular dilatation and degenerative valves and constituted $81.7 \%(n=2866)$ of all MIAS procedures $(n=3507)$. Other groups also reported excellent MIAS repair results for simple and complex AVV procedures, (17) which can also be achieved in the early learning curve. ${ }^{(62-63)}$ Various reports suggest no significant difference in the success of simple or complex AVV procedures whether performed by MIAS or CSA. ${ }^{(57,65)}$

\section{Vascular complications}

Most MIAS reports utilise peripheral retrograde $\mathrm{CPB}$ and obtain safe cardioplegic arrest by either EBAO or DAC. ${ }^{(46)}$ For PAS, the group from Aalst reported an incidence of $0.4 \%$ for aortic dissection, of which the majority occurred during the initial learning curve. ${ }^{(64)}$ Compared with CSA, various conflicting reports suggest that MIAS is associated with increased central aortic or major vascular injury risk. ${ }^{(57,59-61)}$ However, refinements in pre-operative aorto-iliac-axis evaluation strategies, cardiopulmonary bypass techniques, ${ }^{(66-67)}$ the acquisition of guidewire skills and the application of TEE guided cannulation and $E A B O$ placement techniques( ${ }^{(68)}$ significantly decrease the risks of vascular injuries. ${ }^{(69)}$ In addition, it appears that $E A B O$ is associated with less bleeding and vascular injury risks compared with DAC. ${ }^{(70-73)}$

\section{Conversion to classic sternotomy due to adverse MIAS events and its impact on clinical outcome}

The incidence of MIAS conversion to CSA due to adverse intraoperative events ranges considerably, with experienced centres reporting an incidence of $3.0 \%{ }^{(64)}-3.7 \% .^{(17)}$ The group from Aalst suggested an increased mortality associated with conversion during $\mathrm{PAS}^{(64)}$ and also reported their individual conversion rates in the context of complex isolated AVV endocarditis (9.1\%), ${ }^{(74)}$ redo-PAS after previous PAS (19.2\%), ${ }^{(75)}$ difficult access congenital chest wall deformities $(0 \%),{ }^{(76)}$ extreme obesity $(0 \%),{ }^{(77)}$ post-cardiac transplantation $(0 \%)^{(78)}$ and 
hypertrophic obstructive cardiomyopathy with associated AVV disease $(0 \%)$.

\section{Neurological events}

Seeburger and his team observed postoperative neurological impairment in $3.1 \%$ of their MIAS series, ${ }^{(17)}$ of which $2.1 \%$ and $1.0 \%$ were classified as minor and major neurological events (NE) respectively. Various studies report no difference in $N E$, ${ }^{(49,56)}$ transient neuropathy ${ }^{(53)}$ or permanent $N E^{(65)}$ incidence between MIAS and CSA, while isolated reports of a decreased NE incidence following MIAS are also documented. ${ }^{(17,44)}$ However, the recent Society of Thoracic Surgeons-Adult Cardiac Surgical Database (STS-ACSD) report, ${ }^{(61)}$ supported by the Consensus Statement of the International Society of Minimally Invasive Coronary Surgery (ISMICS) $2010^{(79)}$ and other reports, ${ }^{(55-57,59-60)}$ suggest that MIAS does indeed increase NE risk by $0.9 \%$ compared to CSA. Retrograde femoral cannulation was not considered to be an independent predictor of NE.

In addition to pre-operative vascular screening, refinements in de-airing techniques under TEE guidance and operative field $\mathrm{CO} 2$ flooding resulted in improved neurological outcomes. ${ }^{(79)}$ The team from Aalst reported a NE incidence of 1.2\% for their PAS series of 2872 patients. ${ }^{(64)}$ MIAS strategies that utilise antegrade perfusion have low NE risk and excellent outcomes. Recent multi-institutional reports suggest no significant difference in NE between EABO and DAC. ${ }^{(70-73)}$

\section{Cardiac complications}

Various studies compared cardiac outcomes between MIAS and CSA and did not identify any significant difference in the incidence of peri-operative myocardial infarction, low cardiac output syndrome, tamponade or inotropic requirements. ${ }^{(52-53,57)}$ For PAS, the group from Aalst reported their incidence of cardiac death $(0.2 \%)$, acute myocardial infarction $(0.7 \%)$ and low cardiac output syndrome (1.0\%) in their series of 2872 patients. $^{(64)}$

A 10\% incidence of post-operative atrial fibrillation (POAF) was reported for PAS in the PAIR registry, which is lower than CSA reports. ${ }^{(80)}$ Mihos suggested that MIAS for isolated valve surgery reduces postoperative AF and resource use when compared with CSA. ${ }^{(81)}$ Dogan $^{(52)}$ and Chitwood $^{(44)}$ suggested no difference in permanent post-operative pacemaker requirements between MIAS and CSA.

\section{Post-operative bleeding and transfusion requirements}

Extensive post-operative transfusions (POT) and re-exploration for bleeding (RE) are associated with increased mortality and morbidities. ${ }^{(82)}$ Dogan and his colleagues reported significant decrease in chest drain output in MIAS compared to CSA, ${ }^{(52)}$ which was reconfirmed by Glower ${ }^{(56)}$ and other comparative reports. ${ }^{(53-55)}$

It is suggested that the packed red cell units transfused are less with MIAS compared with CSA, ${ }^{(53-55)}$ but the percentage of patients transfused is similar. ${ }^{(52-55,61)}$ Various studies also confirm a significant reduction in RE for bleeding with MIAS compared to CSA, ${ }^{(65,83-85)}$ with the group from Leipzig reporting their RE rate of $5.1 \%{ }^{(17)}$

\section{Respiratory morbidities}

Comparative reports identified no significant difference between MIAS and CSA with regard to the development of post-operative pneumonia, pneumothorax, pleural effusion or other pulmonary complications ${ }^{(86)}$ and it is suggested that ventilation time and subsequent intensive care stay, is significantly reduced with MIAS. ${ }^{(55-60)}$

\section{Gastro-intestinal events}

Comparative reports identified no significant difference between MIAS and CSA with regard to the development of post-operative gastro-intestinal events. ${ }^{(44,53)}$

\section{Renal dysfunction}

McCreath and his colleagues ${ }^{(87)}$ observed a highly significant independent association between surgical approach and renal function, indicating a greater risk of acute renal injury in CSA compared to MIAS performed by PAS, and suggested that PAS may be preferable to conventional methods for patients with high renal risk. Other comparative reports however, identified no significant difference in post-operative renal failure between MIAS and CSA. ${ }^{(57,61)}$

\section{Wound infection}

In a comparative report by Grossi and his colleagues, wound infection occurred in $0.9 \%$ and $5.7 \%$ of MIAS and CSA patients respectively, which increased to $1.8 \%$ for MIAS and $7.7 \%$ for CSA in the elderly. ${ }^{(88)}$ Felger, however, reported no significant difference. ${ }^{(53)}$ Interestingly, the risk of developing mediastinitis ${ }^{(57)}$ and wound dehiscence ${ }^{(59)}$ is reported to be the same for MIAS and CSA. The impact and potential benefit of MIAS in immune-suppressed patients with AVV disease is not yet reported and may indicate a potential wound healing advantage compared with CSA in developing countries.

\section{Duration of hospital stay}

It is suggested that MIAS is associated with decreased intensive care stay, total hospital duration and resource usage compared 
to CSA. ${ }^{(89-92)}$ However, in-hospital stabilisation of anti-coagulation regimes and completion of a 6-week antibiotic course in cases of infective endocarditis, does not reflect the isolated impact on hospitalisation of MIAS. ${ }^{(74-78)}$

\section{In-hospital mortality}

Contemporary reports do not suggest a significant all-cause inhospital mortality difference between MIAS and CSA ${ }^{(52-63)}$ or EBAO and DAC. ${ }^{(70-73)}$ The group from Aalst reported a perioperative mortality of $2.6 \%$ for their PAS series. ${ }^{(64)}$

\section{Post-discharge survival}

Limited comparative reports on long term risk of all-cause mortality between MIAS and CSA are available and do not identify a significant $\mathrm{I}$ - and 3-year survival difference. ${ }^{(45)}$ The group from Aalst reported the intermediate- and long-term PAS survival in the context of infective endocarditis (mean 63.2 \pm 42.5 months, $69.4 \%$ at 10 years), ${ }^{(74)}$ extreme obesity (mean $39.4 \pm 88.4$ months, 100\%), ${ }^{(76)}$ left ventricle outflow tract resection and AVV surgery (mean $49.7 \pm 30.0,100 \%$ ) and redo-PAS after previous PAS (mean $48.3 \pm 39.2$, 95.8\% at 5 years). ${ }^{(75)}$

\section{Freedom from readmission and reintervention}

No significant difference between MIAS and CSA readmission within 30 days, risk of endocarditis or recurrence or need for valve related re-intervention are reported. ${ }^{(44,57,59)}$

\section{Quality of life and patient satisfaction}

Compared with CSA, small thoracic incisions are associated with less pain, discomfort, and postoperative analgesic requirements. ${ }^{(33,53)}$ The group from Aalst suggested that more than $98 \%$ of the patients were extremely pleased with the cosmetic result of PAS, with $42 \%$ reporting an invisible scar, $93 \%$ favourably assessing procedure-related pain and 34\% fully recovered within 4 weeks. ${ }^{(4,16)}$ Faster recovery of patients undergoing MIAS compared to CSA was demonstrated by Glower and his colleagues ${ }^{(56)}$ and it is also reported that patients undergoing MIAS as their second procedure all perceived a faster and less painful recovery than their original CSA, ${ }^{(53)}$ with a small but significant decrease in NYHA class after I year in favour of MIAS compared to CSA. ${ }^{(57-65)}$ The impact of MIAS specific to young patients and rapid recovery are not yet defined and may offer a potential advantage in return to normal duty and productivity in both high-income and low- and middleincome countries compared to CSA.

\section{Healthcare economic implications of MIAS and CSA}

Comprehensive cost-effectiveness analysis of the incremental costs and benefits of MIAS compared to CSA are limited. Atluri and his colleagues demonstrated no difference in total cost (operative and postoperative) between MIAS and CSA ${ }^{(93)}$ and concluded that MIAS can be performed with overall equivalent cost and shorter hospital stay relative to CSA, as the greater operative cost is offset by shorter intensive care unit and hospital stays. Santana demonstrated that MIAS resulted in significant reductions in costs of cardiac imaging and laboratory tests, lower use of blood products, fewer peri-operative infections, faster recovery, shorter hospital length of stay, fewer requirements for rehabilitation and lower readmission rates in the following post-operative year, and concluded that MIAS is safe, effective and significantly more cost-effective than CSA. ${ }^{(94)}$ Grossi suggested that MIAS provides similar mortality, less morbidity, fewer infections, shorter stay, and significant cost savings during primary admission compared to CSA, which translate into additional institutional cost savings. ${ }^{(95)}$ The limited healthcare resources in developing countries may benefit from MIAS and further investigations are warranted.

\section{APPLICATION OF MIAS IN GENERAL SURGICAL PRACTICE - OVERCOMING THE LEARNING CURVE}

Holzney and his colleagues ${ }^{(63)}$ assessed the individual MIAS learning process from 3895 operations performed by 17 surgeons by analysing operation time and complication rates using sequential probability cumulative sum failure analysis. They identified the typical number of operations to overcome the learning curve as ranging between 75 and 125 procedures, and further suggested that more than I procedure per week is required to maintain acceptable results. In addition, they reported that the Individual learning curves varied markedly, proving the need for good monitoring or mentoring in the initial phase.

De Praetere and his colleagues from Leuven ${ }^{(62)}$ assessed the MIAS learning curve by using a logarithmic curve-fit regression analysis of the CPB times, procedure complexity and the number of concomitant procedures. They reported the learning curve to be 30 procedures, with a significant reduction in aortic cross-clamp time before and after the end of the learning curve. The complexity of AVV reconstruction gradually increased and proportion of mitral valve replacements decreased by gradually expanding MIAS indications. They concluded that the transition from CSA to MIAS could safely be introduced into practice without mortality, longer intensive care or hospitalisation.

Hunter reported a systematic approach on how to initiate a MIAS programme ${ }^{(96)}$ and identified techniques of AVV repair, TEE-guided cannulation, incisions, instruments, visualisation, 
aortic occlusion and CPB strategies as seven key aspects to master during the learning curve. He also emphasised the principles of systems awareness, teamwork, communication, ownership and leadership - all of which are paramount to performing safe and effective MIAS.

Murzi ${ }^{(97)}$ applied control charts (CUSUM curves) to monitor individual MIAS surgeon outcomes, with a predetermined acceptable failure rate, alert and alarm lines and clear procedure failure definitions. They identified significant inter-surgeon learning curve variation and concluded that the transition toward MIAS can be performed with low morbidity and mortality.

\section{CONCLUSION}

CSA for AVV disease is well established, but its role in contemporary clinical practice are continuously being redefined by rapid evolution in trans-catheter and MIAS technology, patient preference and industry-driven marketing. However, the routine application of MIAS is met with varying degrees of enthusiasm in view of learning curves, strict quality control, clinical governance and outcome reporting. It is therefore imperative that contemporary international MIAS outcomes are meticulously evaluated for evidence of well-defined patient and healthcare economic benefits - before adopting these techniques into clinical practice. This review confirms the historically reported potential benefits of MIAS compared with CSA and comparable efficacy across a range of long-term efficacy measures such as freedom from reoperation and longterm survival. Surgeons should be encouraged to adopt and apply MIAS in an exciting era of progressive trans-catheter intervention preference, whether in a first- or third-world clinical context.

\section{Conflict of interest: none declared.}

\section{REFERENCES}

I. Falk $\mathrm{V}$, Walther $\mathrm{T}$, Autschbach $\mathrm{R}$, et al. Robot-assisted minimally invasive solo mitral valve operation. J Thorac Cardiovasc Surg 1998; | 15:470-47।.

2. Kypson A, Nifong L, Chitwood Jr. WR. Robotic mitral valve surgery. Surgical Clinics of North America 2003;83(6): I 387-I 403.

3. Kypson A, Felger J, Nifong L, et al. Robotics in valvular surgery: 2003 and beyond. Current Opinion in Cardiology 2004; 19:128-133.

4. Casselman FP, Van Slycke S, Dom H, et al. Endoscopic mitral valve repair: Feasible, reproducible, and durable. J Thorac Cardiovasc Surg 2003;125: 273-282.

5. Chitwood Jr WR, Wixon CL, Elbeery JR, et al. Video-assisted minimally invasive mitral valve surgery. J Thorac Cardiovasc Surg 1997; I I 4(5):773-782.

6. Mack M. Fool me once, shame on you; fool me twice, shame on me! A perspective on the emerging world of percutaneous heart valve therapy. J Thorac Cardiovasc Surg 2008; I36:816-819.

7. Masson JB, Webb JD. Percutaneous treatment of mitral regurgitation. Circ Cardiovasc Interv 2009;2: 1 40-146

8. Feldman T. Percutaneous mitral valve repair. J Interv Cardiol 2007;20: 488-494.

9. Mylotte D, Piazza N. Transcatheter mitral valve implantation: A brief review. Eurolntervention 2015 Sep; I I Suppl W:W 67-70.

10. Vassileva C. Minimally invasive mitral repair: The cost is the same, but what is the price? J Thorac Cardiovasc Surg 20 16;151:389-90.

11. Seder CW, Raymond DP, Wright CD, et al. The Society of Thoracic Surgeons General Thoracic Surgery Database 2017 update on outcomes and quality. Ann Thorac Surg 2017;103(5):1378-1383.

12. Schneider EC, Epstein AM. Use of public performance reports: A survey of patients undergoing cardiac surgery. JAMA 1998;279:1638-1642

13. Jacobs JP, Certfolio RF, Sade RM. The ethics of transparency: Publication of cardiothoracic surgical outcomes in the lay press. Ann Thorac Surg 2009; 87:679-686.

14. Doenst T, Lamelas J. Do we have enough evidence for minimally-invasive cardiac surgery? A critical review of scientific and non-scientific information. J Cardiovasc Surg (Torino) 20 17;58(4):613-623.

15. Bertrand $X$. The future of cardiac surgery: Find opportunity in change!, Eur J Cardiothorac Surg 2013;43(I):253-254.

16. Casselman FP, Van Slycke S, Wellens F, et al. Mitral valve surgery can now routinely be performed endoscopically. Circulation 2003; | 08:||148-1154.

17. Seeburger J, Borger MA, Falk $V$, et al. Minimal invasive mitral valve repair for mitral regurgitation: Results of I 339 consecutive patients. Eur J Cardiothorac Surg 2008;34(4):760-765.

18. Cheng D, Martin J, Lal A, et al. Minimally invasive versus conventional open mitral valve surgery - A meta-analysis and systematic review. Innovations 2011;6:84-103.

19. Modi P, Hassan A, Chitwood WR Jr. Minimally invasive mitral valve surgery: A systematic review and meta-analysis. Eur J Cardiothorac Surg. 2008; 34(5):943-52.

20. Lucà F, Van Garsse L, Massimiliano Rao C, et al. minimally invasive mitral valve surgery: A systematic review. Minimally Invasive Surgery 2013; ID 179569.

21. Brunton L, Edin MD. Preliminary note on the possibility of treating mitral stenosis by surgical methods. Lancet 1902;1:352.

22. Cutler EC, Levine SA. Cardiotomy and valvulotomy for mitral stenosis: Experimental observations and clinical notes concerning an operated case with recovery. Boston Med Surg J 1923: I 88: 1023.

23. Cutler EC, Beck CS. The present state of surgical procedures in chronic valvular disease of the heart: Final report of all surgical cases. Arch Surg 1929; 1 8:403.

24. C. Dubost, D. Guilmet, B. Parades, et al. Nouvelle technique d'ouverture de l'oreillette gauche en chirurgie a coeur ouvert: l'abord bi-auriculair transseptal. La Presse M'edicale 1966;74:1607-1608.

25. Guiraudon GM, Ofiesh JG, Kaushik R. Extended vertical transatrial septal approach to the mitral valve. Ann Thorac Surg 1991;52(5): 1058-1062. 
26. Davila JC, Glower RP. Circumferential suture of the mitral valve for the correction of regurgitation. Am J Cardiol 1958;2:267.

27. Nichols HT. Mitral insufficiency: Treatment by polar cross fusion of the mitral annulus fibrosis. J Thorac Cardiovasc Surg 1957;33:102.

28. Kay EB, Mendelsohn D, Zimmerman HA. Evaluation of the surgical correction of mitral regurgitation. Circulation 1961;23:813.

29. Carpenter A. Cardiac valve surgery: The French Connection. J Thorac Cardiovasc Surg 1983;86:323.

30. McGoon DC. Repair of mitral insufficiency due to ruptured chordae tendineae. J Thorac Cardiovasc Surg 1960;39:357

31. Duran CG, Pomar JL, Revuelta JM. Conservative operation for mitral insufficiency. Critical analysis supported by post-operative hemodynamic studies of 72 patients. J Thorac Cardiovasc Surg 1980;79:326.

32. Navia JL, Cosgrove DM. Minimally invasive mitral valve operations. Ann Thorac Surg 1996;62(5): 1542-1544.

33. Cohn LH, Adams DH, Couper GS, et al. Minimally invasive cardiac valve surgery improves patient satisfaction while reducing costs of cardiac valve replacement and repair. Ann Surg 1997;226(4):421-428.

34. Carpentier A, Loulmet D. First open heart operation (mitral valvuloplasty) under videosurgery through a minithoracotomy. Comptes Rendus de l'Academie des Sciences 1996;319(3):219-223.

35. Stevens $J \mathrm{H}$, Burdon TA, WPeters WS, et al. Port-access coronary artery bypass grafting: A proposed surgical method. J Thorac Cardiovasc Surg |996; | | |:567-573.

36. Mohr FW, Falk V, Diegeler A, et al. Minimally invasive port-access mitral valve surgery. J Thorac Cardiovasc Surg 1998; I I 5(3):567-576.

37. Casselman FP, Van Slycke S, Wellens F, et al. From classical sternotomy to truly endoscopic mitral valve surgery: A step by step procedure. Heart Lung Circ 2003; 12:172-177.

38. Vanermen $H$, Farhat $F$, Wellens $F$, et al. Minimally Invasive video-assisted mitral valve surgery: From port-access towards a totally endoscopic procedure. J Card Surg 2000; 15:51-60.

39. Galloway A, Shemin R, Glower D, et al. First report of the port access international registry. Ann Thorac Surg 1999;67:51-58.

40. Gulielmos V, Wunderlich J, Dangel M, et al. Minimally invasive mitral valve surgery, clinical experiences with port access system. Eur J Cardiothorac Surg 1997; | 4:S| 48-SI53.

41. Angouras DC, Michler RE. An alternative surgical approach to facilitate minimally invasive mitral valve surgery. Ann Thorac Surg 2002;73(2): 673-674.

42. Chitwood Jr WR, Elbeery JR, Chapman WHH, et al. Video-assisted minimally invasive mitral valve surgery: The "micro-mitral" operation. J Thorac Cardiovasc Surg 1997; | |3(2):4|3-4|4.

43. Chitwood WR. State of the art review: Videoscopic minimally invasive mitral valve surgery. Trekking to a totally endoscopic operation. The Heart Surgery Forum 1998; I (I): 13-16.

44. Chitwood Jr WR, Elbeery JR, Moran JF. Minimally invasive mitral valve repair using transthoracic aortic occlusion. Ann Thorac Surg 1997;63(5): |477-1479.

45. Wang $D$, Wang $Q$, Yang $X$, et al. Mitral valve replacement through a minimal right vertical infra-axillary thoracotomy versus standard median sternotomy. Ann Thorac Surg 2009;87(3):704-708.

46. Van Praet K, Stamm C, Sündermann S, et al. Minimally invasive surgical mitral valve repair: State of the art review. Interventional Cardiology Review 2018;13(1):14-19.

47. Carpentier A, Loulmet D, Aup 'ecle B, et al. Computer assisted open heart surgery. First case operated on with success. Minimally invasive surgery. Comptes Rendus de l'Acad'emie des Sciences 1998;321:437-442.

48. Tatooles AJ, Pappas PS, Gordon PJ, et al. Minimally invasive mitral valve repair using the da Vinci robotic system. Ann Thorac Surg 2004;77(6): 1978-1984.

49. Felger JE, Nifong LW, Chitwood Jr WR. The evolution and early experience with robot-assisted mitral valve surgery. Current Surgery 2001;58(6): 570-575.
50. Hamano K, Kawamura T, Gohra H, et al. Stress caused by minimally invasive cardiac surgery versus conventional cardiac surgery: Incidence of systemic inflammatory response syndrome. World Journal of Surgery 2001;25(2): 117-121.

5I. Chaney MA, Durazo-Arvizu RA, Fluder EM, et al. Port-access minimally invasive cardiac surgery increases surgical complexity, increases operating room time, and facilitates early postoperative hospital discharge. Anesthesiology 2000;92: 1637- 1645.

52. Dogan S, Aybek T, Risteski PS, et al. Minimally invasive port access versus conventional mitral valve surgery: Prospective randomised study. Ann Thorac Surg 2005;79:492-498.

53. Felger JE, Chitwood WR Jr, Nifong L, et al. Evolution of mitral valve surgery: Toward a totally endoscopic approach. Ann Thorac Surg 2001;72: 1203-1209.

54. Folliguet $T$, Vanhuyse $F$, Constantino $X$, et al. Mitral valve repair robotic versus sternotomy. Eur I Cardiothorac Surg 2006;29:362-366.

55. Gersak B, Sostaric M, Kalisnik J, et al. The preferable use of port access surgical technique for right and left atrial procedures. Heart Surg Forum 2005;8:282-291.

56. Glower DD, Landolfo KP, Clements F, et al. Mitral valve operation via port access versus median sternotomy. Eur J Cardiothorac Surg. 1998;14 (suppl I):SI43-SI47.

57. Raanani E, Spiegelstein D, Sternik L, et al. Quality of mitral valve repair: Median sternotomy versus port-access approach. J Thorac Cardiovasc Surg 2010; 1 40:86-90.

58. Reichenspurner $\mathrm{H}$, Boehm DH, Gulbins $\mathrm{H}$, et al. Three-dimensional video and robot-assisted port-access mitral valve operation. Ann Thorac Surg 2000;69:1176-1182.

59. Suri RM, Schaff HV, Meyer SR, et al. Thoracoscopic versus open mitral valve repair: A propensity score analysis of early outcomes. Ann Thorac Surg. 2009;88: I 185-। 190.

60. Ryan WH, Brinkman WT, Dewey TM, et al. Mitral valve surgery: Comparison of outcomes in matched sternotomy and port access groups. J Heart Valve Dis. 2010;19:5।-58

6I. Gammie JS, Zhao Y, Peterson ED, et al. Maxwell Chamberlain Memorial Paper for adult cardiac surgery. Less-invasive mitral valve operations: Trends and outcomes from the Society of Thoracic Surgeons Adult Cardiac Surgery Database. Ann Thorac Surg 20 I0;90:140 I- | 408, I 4 I0.el; discussion 1408-1410.

62. De Praetere $H$, Verbrugghe $P$, Rega $F$, et al. Starting minimally invasive valve surgery using endoclamp technology: Safety and results of a starting surgeon. Interact Cardiovasc Thorac Surg 2015;20(3):351-358.

63. Holzhey DM, Seeburger J, Misfeld M, et al. Learning minimally invasive mitral valve surgery: A cumulative sum sequential probability analysis of 3895 operations from a single high-volume center. Circulation 2013;128(5): 483-491.

64. Van der Merwe J, Van Praet F, Stockman B, et al. Reasons for conversion and adverse intraoperative events in Endoscopic Port Access ${ }^{\mathrm{TM}}$ atrioventricular valve surgery and minimally invasive aortic valve surgery. Eur J Cardiothorac Surg 2018;14. doi: 10.1093/ejcts/ezy027. [Epub ahead of print]

65. Grossi EA, LaPietra A, Ribakove GH, et al. Minimally invasive versus sternotomy approaches for mitral reconstruction: Comparison of intermediate-term results. J Thorac Cardiovasc Surg 2001;121:708-713.

66. Gooris T, Van Vaerenbergh G, Coddens J, et al. Perfusion techniques for port-access surgery. Perfusion 1998; 13(4):243-247.

67. Grossi EA, Loulmet DF, Schwartz CF, et al. Evolution of operative techniques and perfusion strategies for minimally invasive mitral valve repair. J Thorac Cardiovasc Surg. 2012;143(4 Suppl): S68-70.

68. Coddens J, Deloof T, Hendrickx J, et al. Transesophageal echocardiography for port-access surgery. J Cardiothorac Vasc Anesth 1999; 13(5):6 | 4-622.

69. Jeanmart H, Casselman FP, De Grieck Y, et al. Avoiding vascular complications during minimally invasive, totally endoscopic intra-cardiac surgery. J Thorac Cardiovasc Surg 2007; I33(4): I066- 1070. 


\section{REFERENCES}

70. Barbero C, Krakor R, Bentala M, et al. Comparison of endoaortic and transthoracic aortic clamping in less-invasive mitral valve surgery. Ann Thorac Surg 20| 8; 105(3):794-798.

71. Casselman F, Aramendi J, Bentala M, et al. Endoaortic clamping does not increase the risk of stroke in minimal access mitral valve surgery: A multicenter experience. Ann Thorac Surg. 2015; I00(4): I 334- 1339.

72. Loforte A, Luzi G, Montalto A, et al. Video-assisted minimally invasive mitral valve surgery: External aortic clamp versus endoclamp techniques. Innovations 2010;5(6):413-4I8

73. Lus F, Mazzaro E, Tursi $V$, et al. Clinical results of minimally invasive mitral valve surgery: Endoaortic clamp versus external aortic clamp techniques. Innovations 2009:4(6):311-318.

74. Van der Merwe J, Casselman F, Stockman B, et al. Endoscopic port access surgery for isolated atrioventricular valve endocarditis. Interact Cardiovasc Thorac Surg 20 18. doi: 10.1093/icvts/ivy1 03. [Epub ahead of print]

75. Van der Merwe J, Casselman F, Stockman B, et al. Late redo-port access surgery after port access surgery. Interact Cardiovasc Thorac Surg 2016;22(1):13-18

76. Van der Merwe J, Casselman F, Stockman B, et al. Endoscopic atrioventricular valve surgery in adults with difficult-to-access uncorrected congenital chest wall deformities. Interact Cardiovasc Thorac Surg 20 I 6;23(6):85 I-855.

77. Van der Merwe J, Casselman F, Stockman B, et al. Endoscopic atrioventricular valve surgery in extreme obesity. Türk Göğüs Kalp Damar Cerrahisi Dergisi 2017;25(4):654-658.

78. Van der Merwe J. Casselman F, Stockman B, et al. Endoscopic port access surgery for late orthotopic cardiac transplantation atrioventricular valve disease. J Heart Valve Dis. 20 17;26(2): 124-129.

79. Falk V, Cheng DC, Martin J, et al. Minimally invasive versus open mitral valve surgery: A consensus statement of the International Society of Minimally Invasive Coronary Surgery (ISMICS) 20 I0. Innovations 201 1;6(2):66-76.

80. Asher CR, DiMengo JM, Arheart KL, et al. Atrial fibrillation early postoperatively following minimally invasive cardiac valvular surgery. American Journal of Cardiology 1999;84(6):744-747.

81. Mihos CG, Santana O, Lamas GA, et al. Incidence of postoperative atrial fibrillation in patients undergoing minimally invasive versus median sternotomy valve surgery. J Thorac Cardiovasc Surg 2013 Dec;146(6): |436-|44|.

82. Murphy GJ, Reeves BC, Rogers CA, et al. Increased mortality, postoperative morbidity, and cost after red blood cell transfusion in patients having cardiac surgery. Circulation 2007; I 6 (22):2544-2552

83. De Vaumas V, Philip I, Daccache G, et al. Comparison of minithoracotomy and conventional sternotomy approaches for valve surgery. Journal of Cardiothoracic and Vascular Anesthesia. 2003; 17(3):325-328.

84. Gaudiani VA, Grunkemeier GL, Castro LJ, et al. Mitral valve operations through standard and smaller incisions. The Heart Surgery Forum 2004;7(4):E337-E342

85. Mihaljevic $\mathrm{T}$, Cohn LH, Unic D, et al. One thousand minimally invasive valve operations: Early and late results. Annals of Surgery 2004;240(3):529-534

86. Cheng DC, Martin J, Lal A, et al. Minimally invasive versus conventional open mitral valve surgery: A meta-analysis and systematic review. Innovations 201 1;6(2):84-103

87. McCreath BJ, Swaminathan M, Booth JV, et al. Mitral valve surgery and acute renal injury: Port access versus median sternotomy. Ann Thorac Surg 2003;75(3):812-819

88. Grossi EA, Galloway AC, Ribakove GH, et al. Minimally invasive port access surgery reduces operative morbidity for valve replacement in the elderly. The Heart Surgery Forum 1999;2(3):212-215.

89. Walther $\mathrm{T}$, Falk $\mathrm{V}$, Metz $\mathrm{S}$, et al. Pain and quality of life after minimally invasive versus conventional cardiac surgery. Ann Thorac Surg 1999;67(6): |643-1647.
90. Yamada T, Ochia Ri, Takeda J, et al. Comparison of early postoperative quality of life in minimally invasive versus conventional valve surgery. Journal of Anesthesia. 2003; 17(3): 17| - 176.

91. Tabata M, Cohn LH. Minimally invasive mitral valve repair with and without robotic technology in the elderly. The American Journal of Geriatric Cardiology 2006; 15(5):306-310.

92. Svensson LG, Atik FA, Cosgrove DM, et al. Minimally invasive versus conventional mitral valve surgery: A propensity matched comparison. J Thorac Cardiovasc Surg 20 10; 139:926-932.

93. Atluri $P$, Stetson RL, Hung $G$, et al. Minimally invasive mitral valve surgery is associated with equivalent cost and shorter hospital stay when compared with traditional sternotomy. J Thorac Cardiovasc Surg 20 I 6; I I I (2):385-388.

94. Santana $O$, Larrauri-Reyes $M$, Zamora $C$, et al. Is a minimally invasive approach for mitral valve surgery more cost-effective than median sternotomy? Interact Cardiovasc Thorac Surg 201 6;22(1):97- 100.

95. Grossi EA, Goldman S, Wolfe JA, et al. Economic Workgroup on Valvular Surgery. Minithoracotomy for mitral valve repair improves inpatient and postdischarge economic savings. J Thorac Cardiovasc Surg 2014;148(6): 28|8-22el-3.

96. Hunter S. How to start a minimal access mitral valve program. Ann Cardiothorac Surg 20 I 3;2(6):774-778.

97. Murzi M, Cerillo AG, Bevilacqua $S$, et al. Enhancing departmental quality control in minimally invasive mitral valve surgery: A single-institution experience. Eur J Cardiothorac Surg 20 I2;42:500-506. 